\title{
ARTICLES
}

\author{
Stanisław Siess-Krzyszkowski \\ Uniwersytet Jagielloński \\ Centrum Badawcze Bibliografii Polskiej Estreicherów \\ stan.siess@uj.edu.pl \\ iD 0000-0002-4309-4268 \\ https://doi.org/10.33077/uw.25448730.zbkh.2021.685
}

\section{Rozmowa Polaka z Włochem Łukasza Górnickiego. Przyczynek do historii edycji}

\section{Rozmowa Polaka z Włochem (A Discussion between a Pole and an Italian) - on the history of editions}

\begin{abstract}
Rozmowa Polaka z Włochem (A Discussion between a Pole and an Italian) is one of the most important political works by Łukasz Górnicki. Written at the end of the $16^{\text {th }}$ century, it was repeatedly reprinted from the $17^{\text {th }}$ century until today. It is also a widely known example of Polish literary plagiatrism: in 1616 Rozmowa was published by Jędrzej Suski as his own work. For a long time Suski edition was considered to be identical with the anonymous version of Rozmowa published sine anno and sine loco, but in 2008 Anna Sitkowa described the actual plagiatrized version with the dedication letter signed by Suski himself. Moreover, typographical analyses of the anonymous version of Rozmowa indicate that it was in fact printed in 1630s, and thus it is not a first, but a third edition of the work. Determining the correct order of editions has significant consequences regarding textual history and criticism.
\end{abstract}

Key words: Lukasz Górnicki - Polish literature of the $16^{\text {th }}$ century - Old Polish bibliography Franz Schnellboltz $-17^{\text {th }}$ century books printed in Toruń

Słowa kluczowe: Łukasz Górnicki - literatura polska XVI w. - bibliografia staropolska Franciszek Schnellboltz - druki toruńskie XVII w. 
Przez wiele lat uznawano, że anonimowa edycja dzieła Łukasza Górnickiego pod tytułem Rozmowa Polaka z Wlochem [sic] O Wolnosciach Y Prawach Polskich ${ }^{1}$, opublikowana bez miejsca i roku wydania, była plagiatem wydanym w 1616 r. przez Jędrzeja Suskiego, przemyskiego pisarza grodzkiego ${ }^{2}$. Powielane od XIX w. nieporozumienie sprostowała ostatecznie Anna Sitkowa ${ }^{3}$, identyfikując w zbiorach Biblioteki Katolickiego Uniwersytetu Lubelskiego rzeczywistą edycję Suskiego (sygn. P. XVI. 19), czyli zdefektowany egzemplarz poprzedzony dedykacją dla Adama Konstantego Ostrogskiego, podpisaną (tak jak zanotował Józef Andrzej Załuski ${ }^{4}$ ): Andrzej Szuski z Rodstwa. Na fakt, że mamy tu do czynienia z dwoma niezależnymi wydaniami, wskazał również wcześniej Jakub Zdzisław Lichański, nie przytaczając jednak żadnych konkretnych informacji odnośnie egzemplarza i nie uzasadniając przyjętej chronologii edycji:

Szczęśliwie udało się niżej podpisanemu odnaleźć autentyczne wydanie Suskiego [zapewne wspomniany wyżej egzemplarz z Biblioteki KUL - SSK]. Stwierdzić możemy, że posługiwał się on anonimowym wydaniem z końca XVI stulecia i że tekstu zasadniczego nie zmienił5.

Wynika z tego niezbicie, że Rozmowa wydana bez miejsca i roku to nie edycja-plagiat Suskiego, lecz bliżej nieokreślone wydanie anonimowe. W polskich bibliotekach zachowało się dziewięć egzemplarzy tej anonimowej edycji. W katalogach bibliotecznych rok druku Rozmowy określany jest rozbieżnie: na koniec XVI w. określają go Biblioteka Ossolineum ${ }^{6}$ i Książnica Kopernikańska w Toruniu, na przełom XVI/XVII w. - Biblioteka Jagiellońska, na r. 1616 lub 1616 ? - Biblioteka Kórnicka, Biblioteka Gdańska PAN, Biblioteka Narodowa oraz Uniwersytecka w Warszawie. Podobne rozbieżności odnotowujemy w literaturze. Roman Pollak zapisał: „Tekst odtwarza anonimowe wydanie Suskiego [sic], które jest niewątpliwie pierwodrukiem z r. 1616"7 , zaś wspo-

1 Ze względów księgoznawczych tytuły cytowanych wydań oraz dawne zapisy bibliograficzne podane są w pisowni niezmodernizowanej.

2 O Suskim zob. M. Kusznierewicz-Mikś, Suski Jędrzej h. Lubicz, [w:] Polski słownik biograficzny. T. 46, Warszawa-Kraków 2009-2010, s. 57-58.

3 A. Sitkowa, Wokót listów dedykacyjnych w edycjach Rozmowy Polaka z Włochem Łukasza Górnickiego z 1616 roku, „Rocznik Przemyski” 2008, t. 44, z. 3: Literatura i język, s. 23-34. Niestety ostatnie wydanie Rozmowy o elekcji [...], wstęp D. Pietrzyk-Reeves, przypisy A. Kuczkiewicz-Fraś (Kraków 2011) nie uwzględnia ustaleń A. Sitkowej.

4 J.A. Załuski, Specyfikacya VI. Lukubracyi w Druku będących Eukasza Górnickiego..., [w:] Ł. Górnicki, Dzieie W Koronie Polskiey za Zygmunta I. y Zygmunta II. Augusta, Aż do śmierci Jego, ... Przez JMci Pána Łukasza Gornickiego ... A teraz nowo wydane Przez J. Z. R. K., Warszawa $1750, \mathrm{k} . \mathrm{a}_{2} \mathrm{v}$.

5 J.Z. Lichański, Sarmacki Castiglione, „Przegląd Humanistyczny” 1982, nr 9, s. 112.

6 Katalog starych druków Biblioteki Zakładu Narodowego im. Ossolińskich. Polonica wieku XVI, oprac. M. Bohonos, Wrocław-Warszawa-Kraków 1965, poz. 881.

7 Pollak R., Noty bibliograficzne i edytorskie, [w:] Ł. Górnicki, Pisma. T. 2, oprac. R. Pollak, Warszawa 1961, s. 729. Edycja Rozmowy w opracowaniu R. Pollaka łączy w sztuczną całość ele- 
mniany J.Z. Lichański: „Górnicki włączył się do powszechnego wtedy nurtu i napisał szybko Rozmowę Polaka z Włochem. Utwór ten ogłosił anonimowo w 1587 lub 1588 r." 8 .

Do odmiennych wniosków prowadzi analiza typograficzna. Przede wszystkim okazuje się, że edycja ta występuje w dwóch wariantach różniących się kartą tytułową.

Wariant a, w którym pod tytułem odbito czworoboczną winietkę linearno-florystyczną (fot. 1) znajduje się w bibliotekach: Gdańskiej PAN, Kórnickiej PAN i Ossolineum. Pozostałe biblioteki posiadają wariant b, w którym pod tytułem odbita została trójkątna winietka linearno-florystyczna (fot. 2) ${ }^{9}$, lub wariant nieokreślony (egzemplarze bez karty tytułowej).

Fot. 1. Karta tytułowa: Rozmowa Polaka $z$ Włochem (wariant a)

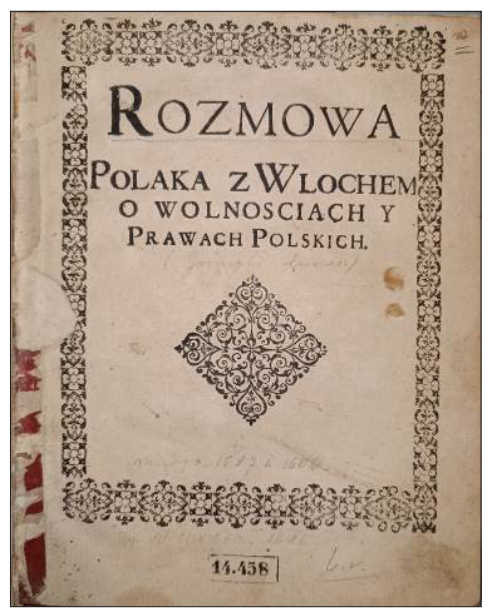

Źródło: Biblioteka Ossolineum Fot. 2. Karta tytułowa: Rozmowa Polaka
z Włochem (wariant b)

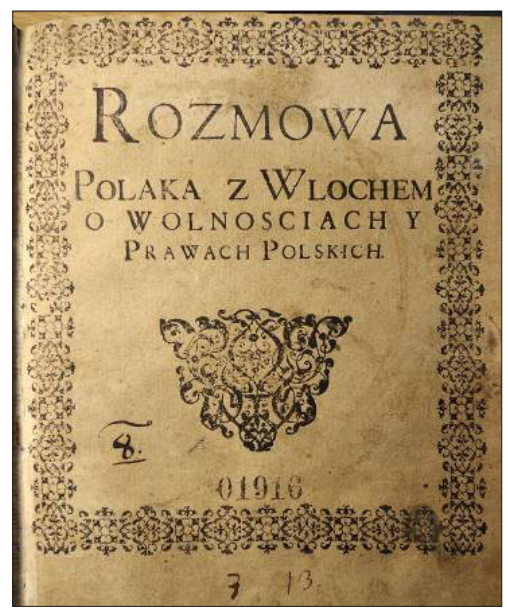

Źródło: Biblioteka Narodowa w Warszawie

Wszystkie elementy zdobnicze użyte do druku Rozmowy znajdujemy w drukach z warsztatu Franciszka Schnellboltza, impresora działającego w latach 1623-1638 w Toruniu. Porównanie kart tytułowych jego druków z lat 1633 i 1634 (fot. 3, 4) z kartą tytułową Rozmów nie pozostawia żadnych wątpliwości.

menty wydania anonimowego (tytuł i tekst zasadniczy) oraz wydania synów Górnickiego (dedykacja i przedmowa do czytelnika).

8 J.Z. Lichański, dz. cyt., s. 112.

9 Wariant b znajduje się również w Bibliotece Ukraińskiej Akademii Nauk im. W. Stefanyka we Lwowie. 
Fot. 3. Karta tytułowa:

Wróżbit boju moskiewskiego (1633)

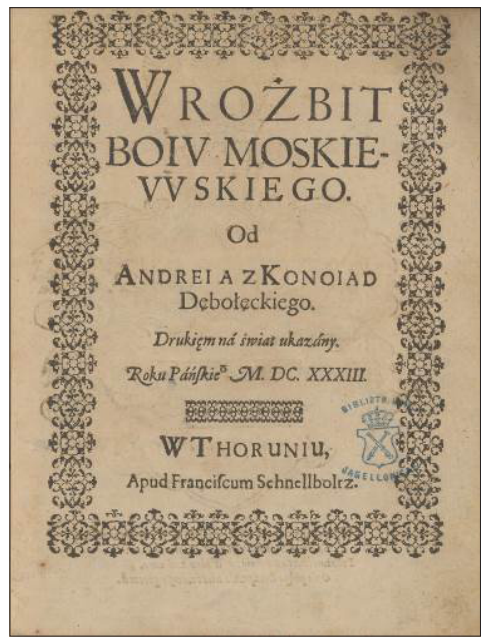

Źródło: Biblioteka Jagiellońska
Fot. 4. Karta tytułowa:

Wieść z Moskwy prawdziwa (1634)

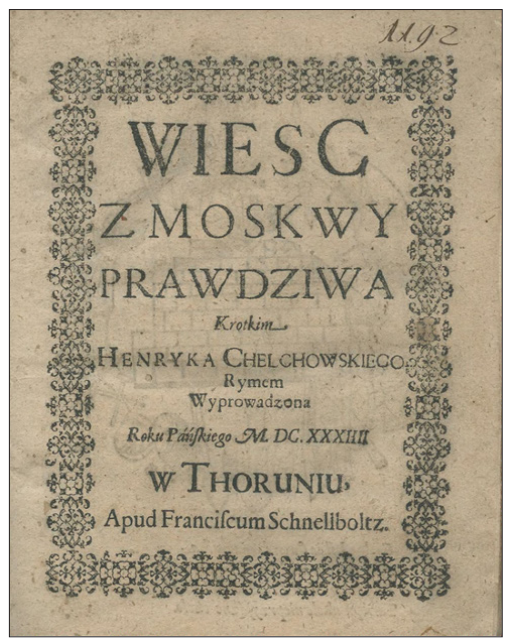

Źródło: Biblioteka Kórnicka PAN

Również winietki ze stron tytułowych obu wariantów i ramki wariantu a Rozmowy znajdujemy w innych drukach Schnellboltza (fot. 5a, 5b, 5c).

Fot. 5a. Winietka (finalik), Plausus Metricus ... Johannis Mathesii ... et ... Drotheae ... Riedt..., Torun: druk. Franciszek Schnellboltz, 1625, karta $\mathrm{A}_{6} \mathrm{~V}$

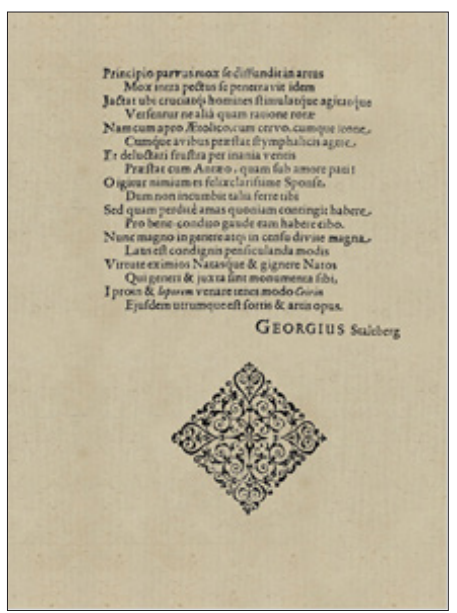

Źródło: Książnica Kopernikańska w Toruniu
Fot. 5b. Listewka,

Wróżbit boju moskiewskiego,

Toruń: druk. Franciszek Schnellboltz, 1633, karta $\mathrm{A}_{2} \mathrm{r}$

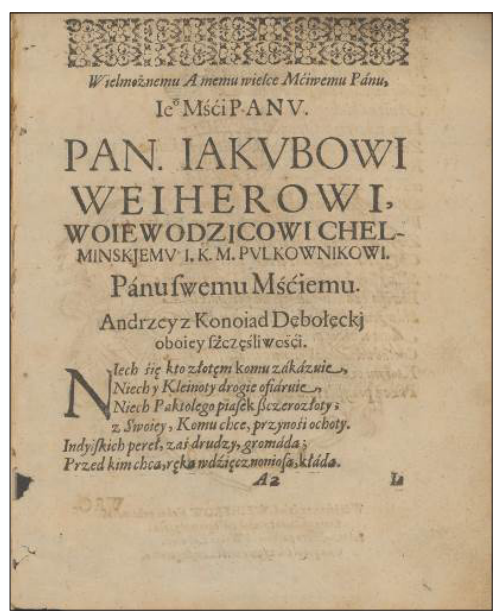

Źródło: Biblioteka Jagiellońska 
Fot. 5c. Winietka (finalik), Wróżbit boju moskiewskiego, Toruń: druk. Franciszek Schnellboltz, 1633, karta $\mathrm{C}_{2} \mathrm{~V}$

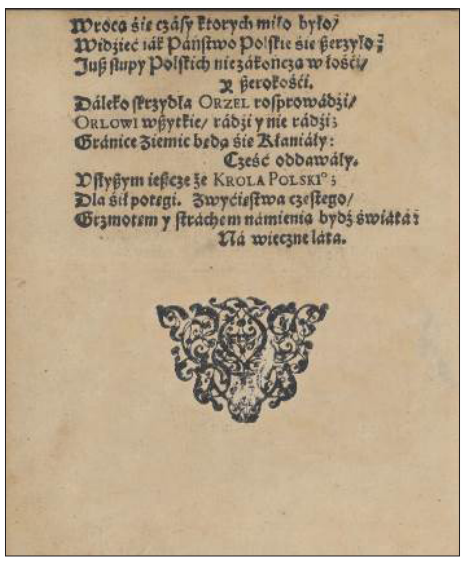

Źródło: Biblioteka Jagiellońska

Natomiast charakterystyczną winietkę, lekko przekrzywiony maszkaron ${ }^{10}$, użytą w Rozmowach jako finalik (fot. 6a) znajdujemy na stronie tytułowej druku z 1614 r. z warsztatu jednego z poprzedników Schnellboltza - Augustyna Ferbera (fot. 6b). Czyli anonimową Rozmowę wydrukowano w Toruniu między 1623 a 1638 rokiem, być może w czasie bezkrólewia 1632 r.

Fot. 6a. Winietka (finalik), Rozmowa

Polaka $z$ Włochem (wariant a i b), s. 102.

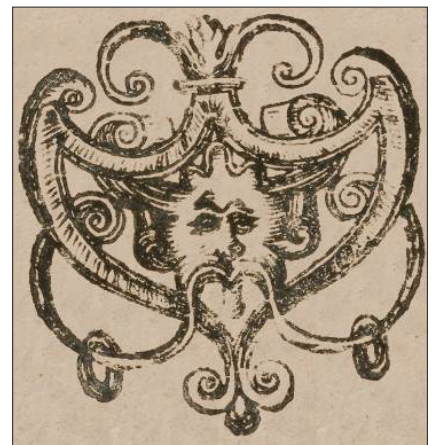

Źródło: Biblioteka Ossolineum
Fot. 6b. Winietka, Nowiny z Poznania, Torun: druk. Augustyn Ferber, 1614, karta tytułowa

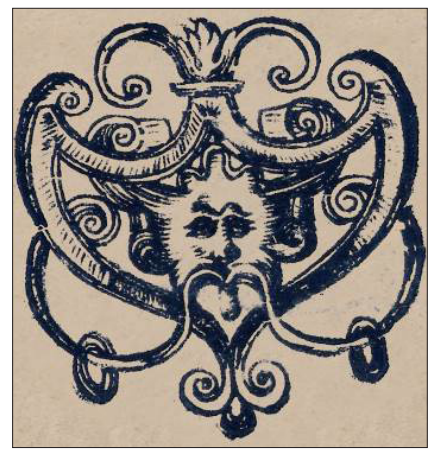

Źródło: Biblioteka Narodowa w Warszawie

10 Winietka ta ma długą historię, znajduje się już w kilku drukach Melchiora Neringa z $1585 \mathrm{r}$. (Nowy Testament, cz. II, finalik), 1586 r. (Lament Mathki Korony Polskiey o śmierci ... Stephana pierszego... Jana Miączyńskiego, finalik) i 1587 r. (Cantional Albo Piesni Duchowne... Piotra Artomiusza, $\mathrm{k}_{\mathrm{M}} \mathrm{\textrm {v }}$ ) oraz Andrzeja Koteniusza z 1587 r. (Epitaphium Stephani I Poloniae Regis Ulderyka Schobera). Biorąc pod uwagę wyłącznie ten charakterystyczny ozdobnik, można odnieść mylne wrażenie, że wspomniane wydanie Rozmowy... opublikowano właśnie pod koniec XVI stulecia. 
Plagiat Suskiego (czyli, jak się okazuje, pierwsze wydanie Rozmowy) ukazał się wiosną 1616 r., a już jesienią wydrukowano w Krakowie odpowiedź synów Górnickiego, Jana i Łukasza: nieco odmienny tekst Rozmowy wydany na podstawie rękopisu, który znajdował się w papierach po ich ojcu. W dedykacji temuż A.K. Ostrogskiemu, któremu dedykował „swoją” Rozmowę J. Suski, synowie wyjaśnili, dlaczego sam Górnicki nie oddał dzieła do druku. W skrócie: tekst traktatu przesłał Górnicki „pod rozsądek” kilku osobistościom i choć Rozmowa

Pochwalona od Ich Mości była [...]. Lecz iż w niej wszystko się to prawie gani, co u nas ludziom najbardziej smakuje [...] rada Ich Mości była: nie podawać zaraz na świat tego pisma [...]. I tak za radą Ich Mości leżał ten traktat odłogiem lat siła, i leżałby był dłużej, gdyby go był w tych dniach jeden szlachcic z Przemyskiej Ziemi [...] za swój wydrukować nie kazał $[\ldots]^{11}$.

Wśród osobistości, którym Górnicki przesłał rękopis dzieła, wymienili jego synowie „Ks. Eustachiego Wołowicza [1571/1572-1630], biskupa wilnieńskiego [od $18 \mathrm{~V} 1616]^{\prime 12}$. Czy był on rzeczywiście jednym z opiniodawców? Jest to raczej nieprawdopodobne - w $1588 \mathrm{r}$. miał on 16 lub 17 lat i zapewne jeszcze pobierał nauki w kolegium jezuickim w Wilnie. Rzeczywistym adresatem był raczej Ostafi Wołłowicz, kanclerz wielki litewski, który świetnie pasuje do innych osobistości wymienionych przez synów Górnickiego: Jana Zamoyskiego, Mikołaja Krzysztofa Radziwiłła czy Marka Sobieskiego. Co więcej, O. Wołlowicz był niegdyś opiekunem prawnym Piotra Wiesiołowskiego (ur. ok. 1548/1550, zm. 1621), którego z Górnickim, mimo różnicy wieku, łączyły przyjacielskie stosunki ${ }^{13}$, a więc Górnicki prawdopodobnie znał kanclerza osobiście. O. Wołłowicz „zmarł na drodze [z Sandomierza do Krakowa] jadąc na koronacyą" Zygmunta III, czyli przed 27 XII 1587 r. ${ }^{14}$ Znaczy to, że Górnicki zakończył pracę nad Rozmową najpewniej w listopadzie 1587 r.

11 Ł. Górnicki, Rozmowa O Elekcyey, o Wolnośći, o Práwie, y obyczáiách Polskich. Pod czás Electiey Krolá Iego Mći Zygmuntá III czyniona. Łukasza Gornickiego, niegdy Tykoćińskiego y Wásitkowskiego Stárosty. Teraz nowo wydána przez Potomki iego, zá pobudka umknienia Tytułu y własnośći Authorá prawdźiwego, Kraków 1616, k. A v.

12 Tamże.

13 Wiesiołowskiemu dedykował Górnicki wydany w 1589 r. przekład tragedii Seneki Troas: „Zacnie urodzonemu Panu, Panu Piotrowi Wiesiołowskiemu, Sekretarzowi Je[g]o Król. M. Panu, i wielkiemu przyjacielowi memu".

14 T. Wasilewski, Testament Ostafiego Wottowicza, „Odrodzenie i Reformacja w Polsce” 1962, t. 7, s. 165-166. Data śmierci Wołłowicza budzi pewne kontrowersje. W liście do Krzysztofa Radziwiłła z datą 29 XI 1587 r. Bohdan Sapieha podał datę: „,20 dnia novembris w Sędomirzu” (Archiwum domu Sapiehów. T. 1, Lwów 1892, nr 34, s. 25). Testament spisany w Sandomierzu przez tegoż Wołłowicza nosi jednak datę 1 XII 1587. Sprzeczność tę można wyjaśnić przyjmując, że list K. Radziwiłła datowany był według starego stylu (czyli 9 XII nowego stylu), zaś data śmierci została źle odczytana i właściwą jest 26 XI według starego stylu (czyli 6 XII nowego stylu). 
Nasuwa się pytanie, która wersja Rozmowy, Suskiego czy synów, jest tekstem pierwotnym. Według R. Pollaka bardziej prawdopodobne wydaje się, że był nim tekst wydany przez Suskiego, a rękopis synów to wersja nieco poprawiona przez Górnickiego po otrzymaniu nieprzychylnych opinii „Ich Mości”, z opublikowania której ostatecznie Górnicki najwyraźniej zrezygnował ${ }^{15}$.

Jak już wspomniałem, druk zachowany w Bibliotece KUL, jedyny znany obecnie egzemplarz wydania Suskiego, jest defektem: brakuje w nim karty tytułowej i karty ostatniej $\left(\mathrm{Aa}_{4}\right)$. W katalogu Biblioteki KUL jest on opisany pod sztucznym tytułem: Rozmowa Polaka z Włochem o wolnościach y prawach polskich (tytuł przejęty z anonimowej edycji Rozmowy). A. Sitkowa posługuje się w swym artykule tym tytułem, który na k. $)\left({ }_{2}{ }_{2} \mathrm{r}\right.$ wymienił w dedykacji do A.K. Ostrogskiego sam Jędrzej Suski: Rozmowa Włocha z Polakiem, o Wolności, prawach, obyczaiach y inszych rzeczach do Polityki nalezacych. Bezsprzecznie pełny egzemplarz plagiatu mieli w rękach Kasper Niesiecki i J.A. Załuski. Niesiecki zanotował: , ,Jędrzej Suski w książce swojej, której dał tytuł Włoch, albo rozmowa Włocha z Polakiem, o swobodach y wolnościach narodu Polskiego w roku 1606 [sic] wydanej [...]"16. Zaś Załuski napisał:

Rozmowa o Elekcyi, o wolnośći, o Prawie y obyczaiach Polskich, podczas Elekcyi Zygmunta III. [in] 4. w Krakowie u Jakuba Sibeneychera 1616.

Andrzej Szuski ${ }^{17}$ przywłaszczył był sobie tę książkę i pod tytułem Włoch albo Dyalog. etc. wydał in 4. w Krakowie 1587. [sic] pag. 181. Z dedykacją księciu Ostrogskiemu: ale że to jest praca Górnickiego, świadczy dedykacja temuż książęciu przypisana od potomków Górnickiego.

Braun $^{18}$, pag. 116. wspomina tę książkę anonyme, ani Górnickiego, ani Szuskiego (plagiarii) imię przywodząc ${ }^{19}$.

Można więc sądzić, że to zapis podany przez Niesieckiego - Włoch, albo rozmowa Włocha z Polakiem, o swobodach y wolnościach narodu Polskiegojest właściwym tytułem wydania Suskiego. Być może na jego stronie tytułowej widniało też nazwisko samego Suskiego, prawie na pewno oznaczone było natomiast miejsce druku - Kraków (por. nota J.A. Załuskiego). Błąd Niesieckiego w oznaczeniu roku wydania to zapewne omyłka drukarska. Rok 1587 podany przez J.A. Załuskiego to data wysnuta z tytułu edycji synów Górnickiego

15 R. Pollak, Wstęp, [w:] Ł. Górnicki, Pisma. T. 1, oprac. R. Pollak, Warszawa 1961, s. 33-34. Tu również bliżej o różnicach między obu wydaniami.

16 K. Niesiecki, Korona Polska [...]. T. 1, Lwów 1728, s. 384.

17 Tak podpisana jest dedykacja A.K. Ostrogskiemu.

18 D. Braun, De Scriptorum Poloniae Et Prussiae Historicorum, Politicorum, \& JCtorum typis impressorum ac Manuscriptorum In Bibliotheca Brauniana Collectorum, Virtutibus Et Vitiis, Catalogus..., Coloniae [recte: Elbląg] 1723.

19 J.A. Załuski, Specyfikacya..., dz. cyt., k. $\mathrm{a}_{2} \mathrm{v}-\mathrm{a}_{3} \mathrm{r}$. 
z 1616 r., wzmiankującej elekcję Zygmunta III, co sugeruje zresztą, że na karcie tytułowej pierwszego wydania rok nie był oznaczony. Datę pod dedykacją Adamowi Konstantemu Ostrogskiemu, 21 III 1616, Załuski najwyraźniej przeoczył.

Pod hasłem Górnicki Łukasz w Bibliografii polskiej Karola Estreichera znajduje się natomiast następujący opis:

Włoch. To iest trzech dni rozmowa na Elekcyi Krola Zygmunta III, o teyże Elekcyi, o wolności, prawie, obyczaiach, y o innych rzeczach temu przyległych Polaka z Włochem. w 4ce, kart 84 .

Katalog Bibl. Krasińskich podaje: w 4ce, k. 4 i str. 181.

Ossol. ${ }^{20}$

Zajmijmy się najpierw egzemplarzem z Biblioteki Ossolineum. Wszystko wskazuje na to, że jest to opis defektowego egzemplarza edycji J.A. Załuskiego z 1750 r. (w 4ce, k. 88), pozbawionego arkusza A i opisanego według tytułu nagłówkowego na k. $\mathrm{B}_{1}$ r. Rzeczywiście w zbiorach Ossolineum nadal znajduje się taki egzemplarz (sygn. XVIII-1844-III).

Bardziej skomplikowana jest sprawa z opisem egzemplarza Krasińskich, najpewniej zniszczonego w r. $1944^{21}$. Bezsprzecznie była to edycja Suskiego, tylko to wydanie liczy bowiem 181 stronic. Ale między opisem egzemplarza Krasińskich a egzemplarza Biblioteki KUL występują drobne, choć istotne różnice. W opisie przesłanym K. Estreicherowi z Biblioteki Krasińskich brak miejsca i roku wydania oraz informacji o dedykacji dla A.K. Ostrogskiego. Ponadto właściwy tekst Rozmowy poprzedzony jest w egz. Krasińskich 4 kartami nl., zaś egz. KUL - 7 kartami nl. (co z brakującą kartą tytułową daje 8 kart nl.). Karty ramy wydawniczej egz. KUL to: Deductio Herbu Pogonia [k. 3: ) ${ }_{2} \mathrm{r}-$ )$\left._{4} \mathrm{v}\right]^{22}$, dedykacja A. K. Ostrogskiemu z datą 21 III 1616 i podpisem: Andrzey Szuski z Rodstwa [k. 2: $)()\left({ }_{1} \mathrm{r}-\right)()\left({ }_{2} \mathrm{v}\right]$, wiersz łaciński In Opus [)()$\left({ }_{3} \mathrm{r}\right]$, Do Czytelnika [)()$\left({ }_{3} \mathrm{v}\right]$ i karta czysta [)()$\left({ }_{4}\right]$.

Ale czy rzeczywiście karta tytułowa tego egzemplarza zgadzała się z zapisem tytułu podanym $u$ Estreichera? Po pierwsze tytuł ten nie zgadza się z tytułem przytoczonym przez Niesieckiego, po drugie - jest identyczny z tytułem nagłówkowym z wydania synów Górnickiego z 1616 r., powtórzonym w wydaniu J.A. Załuskiego z $1750 \mathrm{r}$.

20 K. Estreicher, Bibliografia polska. T. 17, Kraków 1899, s. 254.

21 W opisie Estreichera pomimo wzmianki o katalogu Biblioteki Krasińskich brakuje odpowiedniego bibliotecznego siglum. Być może jest to skutek zwykłego niedopatrzenia, ale nie można wykluczyć, że wspomniany egzemplarz już wówczas nie był dostępny, a biblioteka dysponowała jedynie zapisem katalogowym.

22 Bliżej o tym tekście, najprawdopodobniej pióra J. Suskiego, zob. J. Jurkiewicz, Deductio herbu Pogonia-zapomniany zabytek piśmiennictwa historycznego XVII w., „Белорускі Гістарычны Зборнік” 2015, t. 44, s. 28-44. 
Jak wyjaśnić te różnice? Chyba tylko założeniem, że również egzemplarz Krasińskich nie miał karty tytułowej, a tytuł w opisie był tytułem sztucznym. $\mathrm{Z}$ całą pewnością w egzemplarzu tym nie było dedykacji dla A. K. Ostrogskiego z podpisem Suskiego (Szuskiego) i datą 1616 roku. Czyli prawdopodobnie egzemplarz Krasińskich rozpoczynał się tekstem: Deductio Herbu Pogonia, podobnie jak egzemplarz z Biblioteki KUL.

\section{Zrekonstruowana chronologia staropolskich wydań Rozmowy Polaka z Włochem Łukasza Górnickiego}

1. [Włoch, albo rozmowa Włocha z Polakiem, o swobodach y wolnościach narodu Polskiego], Kraków: b. r. (po 21 III 1616), 4º, k. nl. 8, s. 181 (i. e. 191=k. 96).

Plagiat Jędrzeja Suskiego. Tytuł zrekonstruowany na podstawie opisu K. Niesieckiego.

2. Rozmowa O Elekcyey, o Wolnośći, o Práwie, y obyczáiách Polskich. Pod czás Electiey Krolá Iego Mći Zygmuntá III czyniona. Lukasza Gornickiego, niegdy Tykoćińskiego y Wásitkowskiego Stárosty. Teraz nowo wydána przez Potomki iego, zá pobudka umknienia Tytutu y własnośći Authorá prawdźiwego, Kraków: druk. Dziedzice Jakuba Siebeneichera, 1616 (po 20 VIII), 4º, k. nl. 79.

Wydanie synów Ł. Górnickiego: Jana i Łukasza.

3. Rozmowa Polaka z Wlochem [sic] O Wolnosciach Y Prawach Polskich, b. m. i r. (Torun: druk. Franciszek Schnellboltz, 1632?), 4º, k. nl. 1, s. 102 (wariant a i b).

Anonimowy przedruk wydania J. Suskiego.

4. Rozmowa O elekcyi, o Wolności, o Prawie, y obyczaiach polskich. Podczas Elekcyi Krola Jego Mći Zygmunta III. czyniona. Pisana Przez Łukasza Gornickiego, niegdy Tykocińskiego y Waśitkowskiego Starosty. Teraz nowo wydana y w stylu Staro-Polskim nieco popráwiona przez J. Z. R. K., Warszawa: Druk. Pijarów, b. r. (1750), 4º, k. nl. 88.

Wydanie J.A. Załuskiego - przedruk edycji synów Górnickiego.

\section{Bibliografia}

Estreicher K. st., Bibliografia polska. T. 17, Kraków 1899.

Jurkiewicz J., Deductio herbu Pogonia - zapomniany zabytek piśmiennictwa historycznego XVII w., „Белорускі Гістарычны Зборнік” 2015, t. 44, s. 28-44.

Katalog starych druków Biblioteki Zakładu Narodowego im. Ossolińskich. Polonica wieku XVI, oprac. M. Bohonos, Wrocław-Warszawa-Kraków 1965.

Kusznierewicz-Mikś M., Suski Jędrzej h. Lubicz, [w:] Polski słownik biograficzny. T. 46, Warszawa-Kraków 2009-2010, s. 57-58. 
Lichański J.Z., Sarmacki Castiglione, „Przegląd Humanistyczny” 1982, nr 9, s. 99-117.

Niesiecki K., Korona Polska [...]. T. 1, Lwów 1728.

Pietrzyk-Reeves D., Wstęp, [w:] Górnicki Ł., Droga do zupetnej wolności / Rozmowa o elekcji wolności, prawie i obyczajach polskich, wstęp D. Pietrzyk-Reeves, przypisy A. Kuczkiewicz-Fraś, Kraków 2011, s. VII-XXXVI.

Pollak R., Noty bibliograficzne i edytorskie, [w:] Ł. Górnicki, Pisma. T. 2, oprac. R. Pollak, Warszawa 1961, s. 721-731.

Pollak R., Wstęp, [w:] Górnicki Ł., Pisma. T. 1, oprac. R. Pollak, Warszawa 1961, s. 5-45.

Sitkowa A., Wokót listów dedykacyjnych w edycjach Rozmowy Polaka z Włochem Łukasza Górnickiego z 1616 roku, „Rocznik Przemyski” 2008, t. 44, z. 3: Literatura i język, s. 23-34.

Wasilewski T., Testament Ostafiego Wołtowicza, „Odrodzenie i Reformacja w Polsce” 1962, t. 7, s. 165-173.

Załuski J.A., Specyfikacya VI. Lukubracyi w Druku będacych Łukasza Górnickiego Starosty Tykocińskiego y Waśiłkowskiego Wyięta ex Cathalogo Scriptorum Polonorum Josephi Załuski Ref. Regni, [w:] Ł. Górnicki, Dzieie W Koronie Polskiey za Zygmunta I. y Zygmunta II. Augusta, Aż do śmierci Jego, ... Przez JMci Pána Łukasza Gornickiego ... A teraz nowo wydane Przez J. Z. R. K., Warszawa 1750, k. a $\mathrm{a}_{2} \mathrm{v}-\mathrm{a}_{3}$. 